\title{
The Relationship between Economic Development and Governance Improvement
}

\author{
Qifa Jiang \\ International Business School \\ Yunnan University of Finance and Economics \\ Kunming, China \\ Email: fagenjiang3@163.com
}

\begin{abstract}
Government is critical of importance for economic development. One reason for China's rapid economic development is its experience and practice of governance. In this paper we build a regression model to discuss the relationship between governance improvement and rapid economic development in China. We hypothesize that the relationship will be statistically significant and positive. After testifying, there exists a real relationship between governance and economic development, yet they show different trends partially because of inherent imperfectness of perceptions-based data and "halo-effect" based on our selected governance indicators of the World Governance Index (WGI).
\end{abstract}

Keywords-governance; improvement; economic development; world governance index (WGI); China

\section{INTRODUCTION}

Recent decades witnessed the fast rise of China. As the second largest economy at present, China leaves many interested and explorable questions to the outside world. The biggest puzzle might be why China can grow so quickly with a large population. One of real reasons can be attributed to China's government [1], in accord with the assumption that a GOOD government will be of critical importance for the development [2].

Currently the study of 'good government' shifts into and mainly focuses on a more plausible and ambiguous notion, 'governance', which focuses on government's role, structure and operation process, or the way social problems are resolved [3]. Good governance given its intrinsic value and positive association with the level of development [4], such as reducing endemic corruption and controlling inflation [5], or decreasing transaction costs and enabling markets to work more efficiently [6].

As a process of governing [7], governance and other relevant institutions will shape the direction of economic change as well as evolve incrementally with economy [8]. Though facing many difficulties [9], Chinese economic development will largely show how governance accounts for their economies, and hence reflect the evolution of their governance.

Experience and practice of governance and development in China are valuable to other developing countries; China does represent an alternative development model, especially when considering it also started at a poor condition [10]; and it will provide both positive and negative lessons for other societies that are facing similar problems [11].

However, few studies will concentrate on issues that governance of a country will change with economic development, or, more formally, issues of governance improvement, e.g. the role of China's government and the style of governance in the process of development. Therefore, this paper will mainly discuss the question of the relationship between governance improvement and rapid economic development in China. We will firstly introduce the data, and then construct the model, finally positively examine the relationship discussed in this paper.

\section{THE DATA}

Our goal is to examine the relationship between economic development and governance improvement in China, so we will use the World Governance Indicators (WGI) - a set of comprehensive indicators to evaluate a country's governance to measure governance; also we will adopt economic growth rate and GDP per capita to represent economic development.

\section{A. The World Governance Indicators (WGI)}

The Worldwide Governance Indicators (WGI) project (www.govindicators.org) reports aggregate and individual governance indicators for over 200 countries and territories over the period 1996-2016, for six dimensions of governance as: (D1) Voice and Accountability; (D2) Political Stability and Absence of Violence; (D3) Government Effectiveness; (D4) Regulatory Quality; (D5) Rule of Law; (D6) Control of Corruption [12].

The annual scores of WGI for China are shown as below in Table 1, where we collect WGI scores of six dimensions together. The data of WGI from 1996 to 2016 has missed the data of 3 years: 1997, 1999, 2001.

\footnotetext{
*Corresponding author
} 
TABLE I. THE WGI AND ITS AVERAGE FOR CHINA

\begin{tabular}{|l|c|c|c|c|c|c|c|c|c|c|c|c|c|c|c|c|c|c|c|c|c|}
\hline Year & 1996 & 1997 & 1998 & 1999 & 2000 & 2001 & 2002 & 2003 & 2004 & 2005 & 2006 & 2007 & 2008 & 2009 & 2010 & 2011 & 2012 & 2013 & 2014 & 2015 & 2016 \\
\hline D1 & -1.36 & & -1.44 & & -1.38 & & -1.59 & -1.51 & -1.46 & -1.50 & -1.75 & -1.72 & -1.70 & -1.70 & -1.68 & -1.64 & -1.64 & -1.63 & -1.62 & -1.66 & -1.62 \\
\hline D2 & -0.10 & & -0.39 & & -0.21 & & -0.33 & -0.56 & -0.39 & -0.50 & -0.54 & -0.50 & -0.49 & -0.45 & -0.66 & -0.60 & -0.54 & -0.54 & -0.52 & -0.55 & -0.52 \\
\hline D3 & -0.35 & & -0.12 & & -0.11 & & -0.06 & -0.08 & -0.06 & -0.12 & 0.07 & 0.18 & 0.15 & 0.09 & 0.09 & 0.09 & 0.02 & 0.00 & 0.32 & 0.41 & 0.36 \\
\hline D4 & -0.27 & & -0.30 & & -0.34 & & -0.51 & -0.33 & -0.31 & -0.15 & -0.20 & -0.17 & -0.15 & -0.22 & -0.23 & -0.22 & -0.24 & -0.29 & -0.28 & -0.29 & -0.26 \\
\hline D5 & -0.55 & & -0.46 & & -0.53 & & -0.50 & -0.53 & -0.53 & -0.59 & -0.64 & -0.54 & -0.42 & -0.41 & -0.41 & -0.46 & -0.54 & -0.52 & -0.41 & -0.41 & -0.22 \\
\hline D6 & -0.27 & & -0.27 & & -0.22 & & -0.52 & -0.36 & -0.56 & -0.61 & -0.51 & -0.59 & -0.52 & -0.51 & -0.56 & -0.51 & -0.44 & -0.36 & -0.34 & -0.28 & -0.25 \\
\hline Unweighted & -0.48 & & -0.50 & & -0.46 & & -0.59 & -0.56 & -0.55 & -0.58 & -0.60 & -0.56 & -0.52 & -0.53 & -0.58 & -0.56 & -0.56 & -0.56 & -0.48 & -0.46 & -0.42 \\
\hline Average
\end{tabular}

${ }^{\text {a. }}$ Source: The Worldwide Governance Indicators (WGI) (www.govindicators.org). The highest score is 2.5, and the lowest score is -2.5 .3 years data has missed: 1997, 1999, 2001.

b. The data of WGI from 1996 to 2016 has missed the data of 3 years: 1997, 1999, 2001

There still might exist a question: how can we transform WGI of six dimensions to a single composite governance index? The best solution might determine the weights for indicators of each dimension, or the effects/consequences of extending the methodology on how indicators weigh in the end result, which needs to look at what happens in terms of margin of error for an overall governance estimate [13]. To simplify the question, we can just use an ease way: we can weight each dimension equally important and then get its unweighted average of all 6 dimensions.

\section{B. The Data for Economic Development}

Generally there are two indicators which can reflect the economic development: Gross Domestic Product (GDP) per capita and economic growth rate. We adopt these data from the World Bank Database (https://data.worldbank.org/), which is an "analysis and visualization tool that contains collections of time series data on a variety of topics" and well accepted all over the world.

Table 2 shows the data of economic development: real economic growth rate and the correspondent data of GDP per capita, PPP, from 1996 to 2016, at 2010 constant US dollar, which can eliminate the price effects.

TABLE II. THE 2010 CONSTANT GDP PER CAPITA FOR CHINA

\begin{tabular}{|c|c|c|c|c|c|c|c|c|c|c|c|c|c|c|c|c|c|c|c|c|c|}
\hline Year & 96 & 997 & 998 & 999 & 2000 & 2001 & 2002 & 2003 & 2004 & 2005 & 2006 & 2007 & 2008 & 2009 & 2010 & 2011 & 2012 & 2013 & 2014 & 2015 & 2016 \\
\hline owth Rate & .95 & 93 & .23 & 7.84 & 7.67 & 8.49 & 8.34 & 9.13 & 0.04 & 10.11 & 1.40 & 12.72 & 4.23 & 9.65 & 9.40 & 10.64 & 9.5 & 7.86 & 7.76 & 7.39 & 6.90 \\
\hline $\begin{array}{l}\text { DP per } \\
\text { pita (\$) }\end{array}$ & & & & & & & & & & & & & & & & $\mathrm{DI}$ & & & & 6108.24 & 6496.62 \\
\hline
\end{tabular}

c. Source: The World Bank Databank (https://data.worldbank.org/), data from 1996 to 2006.

d. GDP per capita is at 2010 constant US dollar.

\section{THE MODEL}

Assume the improvement of governance will be linearly relevant to the economy. When examining the relationship between governance and economic development, we can set up the following formula:

$$
y_{G}=\beta_{0}+\beta_{1} x_{r}+\beta_{2} x_{p}+\varepsilon_{i}
$$

Here, $y_{G}$ denotes governance indicator of the WGI,

$x_{r}$ denotes economic growth indicator, e.g. economic growth rate,

$x_{p}$ denotes GDP per capita.

The data shows in Table $1 \& 2 . y_{G}$ is the data of unweighted average WGI from 1996 to 2016, yet missing the data of 3 years: 1997, 1999, 2001. $x_{r}$ is the data for economic growth rate, and $x_{p}$ for the correspondent data of GDP per capita, 2010 constant US dollar, from 1996 to 2016, which can eliminate the price effect.

In the data processing we expect that:

- there is a real relationship between WGI and economic growth, e.g. the relationship is statistically significant.

- the relationship is positive, e.g. the coefficient of $\beta_{1}, \beta_{2}>0$.

\section{FINDINGS}

After regression analysis, we can analyze the final results which shows in Figure 1, and Table 3. Then, we can conclude that:

- WGI scores are fairly low for China. The average score is -0.53 , which is not currently matched with the economic and social status of China internationally. 
- Based on time-series analysis, the trendline represents slightly upward over years; and WGI improved quickly in recent years (actually recovery from 2010).

- There is a good relationship between WGI and economic growth which is indicated by economic growth rate and GDP per capita, with the fact that $\mathrm{R}$ square larger than 0.40 .

- However, contrary to the reality of increasingly economic development in China, the relationship second hypothesis testifying why the final results will challenge our initial expectations. shows negative between dependent and independent variables, e.g. $\beta_{1}, \beta_{2}<0$. The economic growth rate will exert mild impacts on the governance improvement, yet little impact in terms of GDP per capita.

\section{DISCUSSION}

In this section we will further discuss the issues of our selected data of WGI, and try to give some explanation for the

0

199619971998199920002001200220032004200520062007200820092010201120122013201420152016 $-0.1$

$-0.2$

$-0.3$

$-0.4$

$-0.5$

$-0.6$

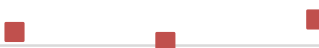

$-0.7$

e. Source: The Worldwide Governance Indicators (WGI) (www.govindicators.org). The highest score is 2.5 , and the lowest score is -2.5 . The straight line is the trendline of WGI for China.

Fig. 1. Time-series data of WGI in China

TABLE III. RESULTS OF THE REGRESSION ANALYSIS

\begin{tabular}{|l|r|}
\hline \multicolumn{2}{|c|}{ Regression Statistics } \\
\hline Multiple R & 0.635751 \\
\hline R Square & 0.40418 \\
\hline Adjusted R Square & 0.324737 \\
\hline Standard Error & 0.041741 \\
\hline
\end{tabular}

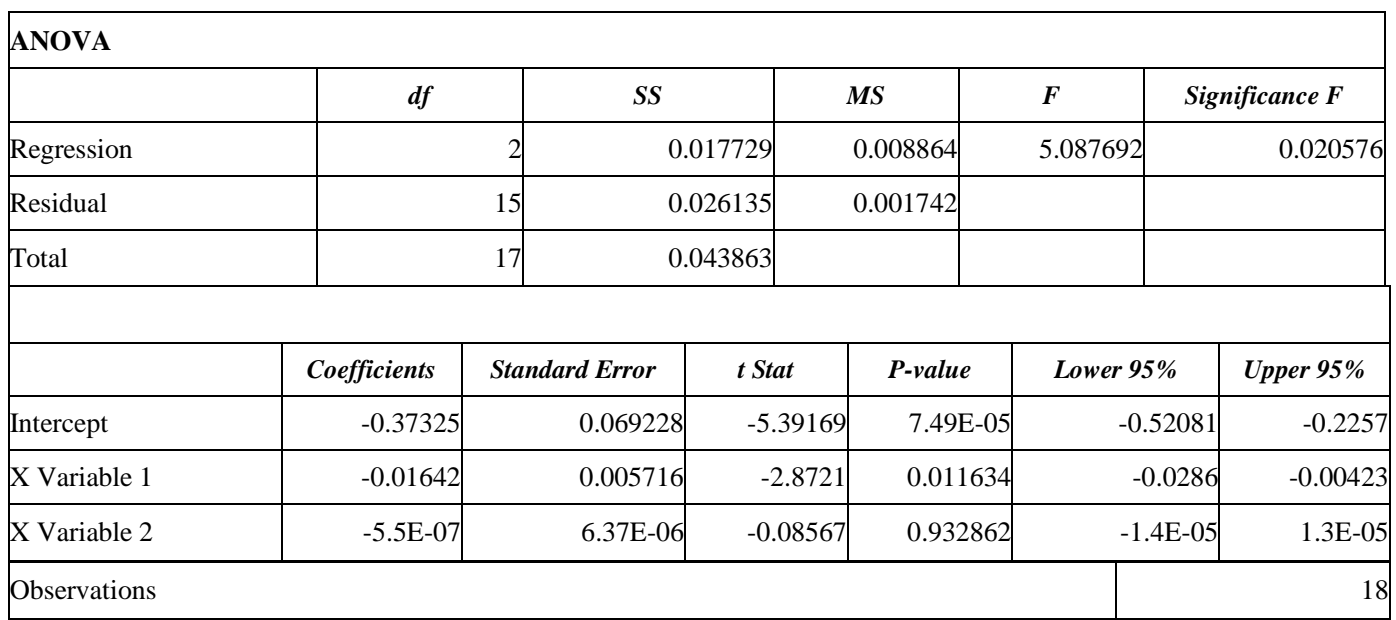




\section{A. Selected Indicators of WGI}

As mentioned above, it is quite difficult to conceptualize and measure governance. Our selected indicators of WGI then possess intrinsic weaknesses due to the inherently unobservable nature of the facts of governance in a country; its measurement will only be an imperfect proxy for the exact status of governance [14]. For example, the data of China is frequently questioned by many researchers [13; 15], sometimes as the 'Puzzle with China' [16]. Other potential weaknesses are that, there might be some measurement errors [17], and too much "subjective" data [14], etc.

\section{B. Explanation of Hypothesis Testifying}

To some extent, WGI can be regarded as an image of a nation, thus some China's hot issues such as high economic growth might impress positive images for the people all over the world, particularly in recent years. The issues of perceptions-based data and "halo-effect" has been discussed by other researchers [14].

Because of its differences in cultural, political and economic systems, when China becomes more and more rich, Western people are changing their minds and increasingly taking positive views on Chinese people. Yet with higher GDP per capita, China's economic growth rate will slow down consequentially. Therefore, the dependent variable, governance improvement, will turn an inconsistent trend with the independent variables, economic development, which is mainly indicated by economic growth rate.

In order to more precisely examine the relationship between dependent and independent variables, more variables, probably such as the factors of culture, religion, the economic situations, etc. should be taken into account when constructing the regression model. Another potential solution can conduct a panel data analysis for cross countries, yet there still might be some questions to be solved on this issue [17].

\section{CONCLUSIONS}

Government plays a critical role in economic development with the rise of China. China does represent an alternative development model, and it will provide both positive and negative lessons for other societies. Its experience and practice of governance can afford valuable lessons to other developing countries.

Few studies will concentrate on issues of governance changing with economic development. In this paper we set up a regression equation to analyze the relationship between governance improvement and rapid economic development in China. We use the data for economic growth rate and GDP per capita from the World Bank Database (https://data.worldbank.org/) which represent economic development, and adopt the Worldwide Governance Indicators (WGI) (www.govindicators.org) to measure governance. After positively examine the relationship discussed in this paper, we can conclude that:

- Owing to its ambiguity to conceptualize, it is hard to get a perfect indicator to measure governance. The WGI also has the attributes of perfectness due to its
Another important aspect is that these indicators are much more reliant on some ideological principles rather than performance-orientation [14]. For example, basically this philosophy of assessment-constructed system might assume that governance should be independent of economic development, therefore there are just few indicators relevant to economic development in the 4th dimension of 'Regulatory Quality'.

However, in this paper we just would plan to find the relationship between governance improvement and economic growth, so it could be suitable to cite the data.

inherently unobservable nature and too much "subjective" data. It is just suitable for our explorable study.

- Because of different cultural, political and economic systems, China gets an average WGI score of -0.53 . This is not consistent with the economic and social situations of China in the world nowadays.

- Based on our data, there is a real relationship between governance and economic development. In our study, the key parameter, $\mathrm{R}$ square, is more than 0.40 .

- However, the economic development and governance shows different trends: The economic growth rate will exert mild impact on the governance improvement, yet little in terms of GDP per capita. The reason this point will challenge our hypothesis partially is the issues of perceptions-based data and "halo-effect" of WGI: with higher GDP per capita, Western people become increasingly positive views on China when its economic growth rate will slow down.

New factors such as culture, religion, and economic variables, etc. should be considered when building the regression model to more precisely test the relationship between governance improvement and economic development And might other potential solutions can be introduced such as cross-country analysis.

\section{ACKNOWLEDGEMENT}

This work is supported by National Natural Science Foundation of China (NSFC) under Grant 71463061 and China Scholarship Council (CSC NO: 201608535060).

\section{REFERENCES}

[1] Wing Thye Woo, "THE REAL REASONS FOR CHINA'S GROWTH", The China Journal, Vol. 41, pp. 115-137, January 1999.

[2] G. Hyden \& J. Court, "GOVERNANCE AND DEVELOPMENT". World Governance Survey Discussion Paper 1, Tokyo, Japan: United Nations University, 2002.

[3] C. Heinrich and Jr. L. Lynn, Governance and Performance: New Perspectives, Washington D.C.: Georgetown University Press, 2000.

[4] Zhuang Juzhong, Emmanuel de Dios and Anneli Lagman-Martin, "Governance and Institutional Quality and the Links with Economic Growth and Income Inequality: With Special Reference to Developing Asia”, ADB Economics Working Paper Series No. 193, Metro Manila, Philippines: Asian Development Bank: February 2010. 
[5] Azam Muhammad \& Chandra Emirullah, "The role of governance in economic development", International Journal of Social Economics, Vol 41, Iss. 12, pp. 1265 - 1278, 2014.

[6] Mushtaq H. Khan, "Governance, Economic Growth and Development since the 1960s", UN/DESA Working Papers No. 54, New York: United Nations, August 2007.

[7] B. G. Peters \& J. Pierre, "Governance Without Government? Rethinking Public Administration", Journal of Public Administration Research and Theory: J-PART, Vol. 8, No. 2, pp. 223-243, 19983.

[8] D. North, Institutions, Institutional Change and Economic Performance, Cambridge: Cambridge University Press, 1990, pp. 3-10.

[9] Julan Du, Hongsheng Fang \& Xiangrong Jin, "Chinese Political and Economic Governance System and the Imhalance hetween Concumntion and Investment”, Working Papers 232013, Hong Kong, China: Hong Kong Institute for Monetary Research, 2013.

[10] $\mathrm{He} \mathrm{Li,} \mathrm{"The} \mathrm{Chinese} \mathrm{Model} \mathrm{of} \mathrm{Development} \mathrm{and} \mathrm{Its} \mathrm{Implications",}$ World Journal of Social Science Research, Vol. 2, No. 2, pp. 128 - 138, 2015.

[11] Ting Gong, Paul Collins \& Hon S. Chan, "THE QUALITY OF GOVERNANCE IN CHINA AND BEYOND: INTRODUCTION TO SPECIAL ISSUE", Public Administration and Development, 37, pp. 155-159, 2017.
[12] Daniel Kaufmann, Aart Kraay and Massimo Mastruzzi, "The Worldwide Governance Indicators: Methodology and Analytical Issues", World Bank Policy Research Working Paper No. 5430, Washington, D.C., USA: World Bank, September 2010.

[13] Mattias Ottervik, "Conceptualizing and Measuring State Caapacity: Testing the Validity of Tax Compliance as a Measure of State Capacity", WORKING PAPER SERIES 2013:20, Gothenburg, Sweden: The Quality of Government Institute (QOG), 2013.

[14] Daniel Kaufmann, Aart Kraay and Massimo Mastruzzi, "Worldwide Governance Indicators Project: Answering the Critics", World Bank Policy Research Working Paper No. 4149, Washington, D.C., USA: World Bank, March 1, 2007.

[15] Francis Fukuyama, "What is Governance?", Governance: An International Journal of Policy, Administration, and Institutions, 26(3), pp. 347-368, 2013.

[16] Bo Rothstein, "Understanding the Quality of Government in China: The Cadre Administration Hypothesis", Working Paper Series 2012:17, University of Gothenburg, Gothenburg: The Quality of Government Institute, 2012.

[17] Xuehui Han, Haider Khan and Juzhong Zhuang, "Do Governance Indicators Explain Development Performance? A Cross-Country Analysis", ADB Economics Working Paper Series No. 417, Metro Manila, Philippines: Asian Development Bank, 2014. 